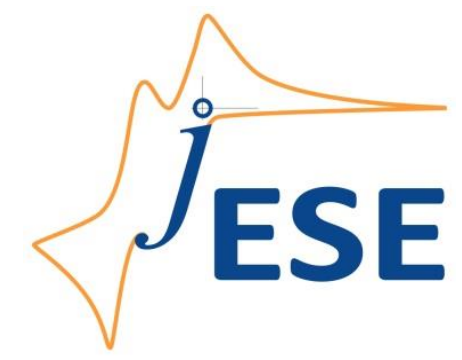

Open Access : : ISSN 1847-9286

www.jESE-online.org

Original scientific paper

\title{
Pattern formation during electrodeposition of copper-antimony alloys
}

\author{
Vasil S. Kostov, Ivan N. Krastev, Tsvetina V. Dobrovolska ${ }^{凶}$ \\ Institute of Physical Chemistry, Bulgarian Academy of Sciences, Sofia 1113, Bulgaria \\ ${ }^{\otimes}$ Corresponding Author: tsvetina@ipc.bas.bg
}

Received: August 17, 2015; Revised: January 8, 2016; Accepted: February 8, 2016

\begin{abstract}
Aim of the present study is to establish the conditions of the electrolysis for the preparation of structured and unstressed purple-pink coatings of copper-antimony alloys, including their phase characterization. Also the task of the present investigation is, by changing drastically the metal content in the methanesulfonic electrolyte to find out the conditions of electrolysis where the self-organization of the different phases is expressed by higher-order structures - not only waves but also spirals and targets. The possibility to obtain copper-antimony alloy with up to $80 \mathrm{wt}$. \% Sb from methanesulfonic acid is shown. The deposition rate, morphology and the phase composition of the obtained coatings are established. The phenomena of formation of spatio-temporal structures in this alloy are described.It is determined that the observed structures consist of $\mathrm{Cu}_{2} \mathrm{Sb}$ and $\mathrm{Cu}_{11} \mathrm{Sb}_{3}$ intermetallic phases.
\end{abstract}

\section{Keywords}

Electrodeposited alloy; Copper-antimony; Self-organization phenomena

\section{Introduction}

This study is a continuation of previous attempts to co-deposit electrochemically copper with antimony. Electrochemical deposition of this system was recently presented by Hrussanova et al. [1]. They, after a brief review about the electrodeposition processes in these alloys, presented the investigation on the electrodeposition of $\mathrm{Cu}-\mathrm{Sb}$ alloys from acid methanesulfonic electrolytes and the obtained coatings indicated the presence of optical heterogeneity. The observed phenomenon in its initial stages of structure formation is very similar to those observed in other electrodeposited systems like Ag-Sb, Ag-In, In-Co and etc. [2-8]. Based on the same type of electrolyte the goal of the present investigation is, by changing drastically the metal content in the 
electrolyte, to find out the conditions of electrolysis where the self-organization of the different phases is expressed in the form of higher-ordered structures - not only waves, but also spirals and targets. Nowadays, it has been shown that the structure formation in the electrodeposited alloys occurs as a result of a reaction-diffusion mechanism where the presence of intermetallic compounds in the alloy plays a key role [9]. The phase diagram of the Cu-Sb system shows the presence of a few intermetallic compounds stable at room temperature as well as several hightemperature phases [10]. The present study has also the task to find out the possibility to obtain unstressed (without cracks) coatings with pinkish-purple color. The establishment of wellfunctioning non-toxic electrolytes for colored tarnish resistive alloys of non-noble metals is a challenge in the modern electroplating [11,12]. Aim of the present study was to establish the conditions of the electrolysis for the preparation of structured and unstressed purple-pink coatings on the alloy $\mathrm{Cu}-\mathrm{Sb}$, including their phase characterization.

\section{Experimental}

The composition of the electrolytes for the deposition of the alloy coatings is presented in Table1. Distilled water and pro analisi grade reagents were used for the preparation of the electrolytes. The CV experiments were performed in a $100 \mathrm{~cm}^{3}$ tri-electrode glass cell at room temperature. The working electrode (area $1 \mathrm{~cm}^{2}$ ) was made from platinum and the two counter electrodes were made from platinum. $\mathrm{Ag} / \mathrm{AgCl}$ reference electrode $\left(\mathrm{E}_{\mathrm{Ag} / \mathrm{AgCl}}=0.197 \mathrm{~V} v \mathrm{~s}\right.$. $\left.\mathrm{NHE}\right)$ was used.

Table 1. Composition of the electrolyte

\begin{tabular}{lc}
\hline \multicolumn{1}{c}{ Components } & Concentration, $\mathrm{g} \mathrm{dm}^{-3}$ \\
\hline $\mathrm{Sb}$ as $\mathrm{K}(\mathrm{SbO}) \mathrm{C}_{4} \mathrm{H}_{4} \mathrm{O}_{6} 1 / 2 \mathrm{H}_{2} \mathrm{O}$ & 27 \\
$\mathrm{Cu}$ as $\mathrm{CuSO}_{4} 5 \mathrm{H}_{2} \mathrm{O}$ & 2.4 \\
Methanesulfonic acid & 20 \\
$\mathrm{D}(-)-\mathrm{C}_{4} \mathrm{H}_{6} \mathrm{O}_{6}$ & 96 \\
\hline
\end{tabular}

The experiments were performed by means of a computerized potentiostat/galvanostat Princeton Applied Research Model 273 using the software PowerSuite.

The alloy coatings with thickness between 3 and $25 \mu \mathrm{m}$ were deposited onto brass substrates with an area of $2 \times 1 \mathrm{~cm}$ in the glass cell. The preliminary preparation of the cathodes includes a standard procedure of electrochemical degreasing followed by pickling in a $20 \%$ solution of sulphuric acid. Two Pt (Ti) counter electrodes (about $4 \mathrm{~cm}^{2}$ each) were used.

The content of antimony (respectively copper) (as well as the thickness) in the coatings depending on the electrolysis conditions, was determined by X-ray fluorescence analysis (Fischerscope X-RAY XDAL) in 3 points (in the bottom, middle and top of the sample, respectively). The electrode is situated vertically and at the 'bottom' means the closest point to the electrical contact. The $\mathrm{Sb}$ or $\mathrm{Cu}$ distribution on the surface of the coatings was examined by energy dispersive X-ray analysis (EDX).

The surface morphology of the coatings was investigated by scanning electron microscopy (SEM) - JEOL JSM 6390. The phase composition was characterized by X-ray diffraction (XRD) using a PANalytical Empyrean device equipped with a multichannel detector (Pixel 3D) using Cu-K $\alpha$ $(45 \mathrm{kV}, 40 \mathrm{~mA})$ irradiation in the $2 \theta$ range $20-115^{\circ}$, with a scan step of $0.01^{\circ}$ for $20 \mathrm{~s}$. 


\section{Results and discussion}

Figure 1 presents the cyclic voltammetry curves of the electrolytes, containing both metals separately and together. The electrodeposition of antimony starts at about $-0.5 \mathrm{~V}$ (curve 1 ) and the maximum of the reaction is characterized by the current peak at $-0.8 \mathrm{~V}$; the reduction of copper ions starts earlier (curve 2). The curve of the alloy electrodeposition follows the run of the copper curve at low potentials and after reaching the deposition potential of antimony runs similar to the antimony curve. The coatings of copper and antimony, deposited in the cathodic period are dissolved in the anodic region. Only one dissolution peak $(0.4 \mathrm{~V}$ for the antimony dissolution and $0.65 \mathrm{~V}$ - for the copper dissolution) could be seen in the electrolytes with single metals. The oxygen evolution reaction in the investigated region of the potentials is not reached. In the alloy electrolyte, containing both metals at the beginning of the process up to $-0.4 \mathrm{~V}$ the curve almost repeat the run of the curve in the copper-containing electrolyte. The sharply increase of the current continues up to the $-0.7 \mathrm{~V}$. This potential corresponds to the maximum of the observed cathodic peak in the alloy electrolyte and most probably, belongs to the formation of some alloy phase. In the anodic period only one very broad anodic peak of the dissolution of all formed in the cathodic period phases of $\mathrm{Cu}, \mathrm{Sb}$ and some intermetallides are observed.

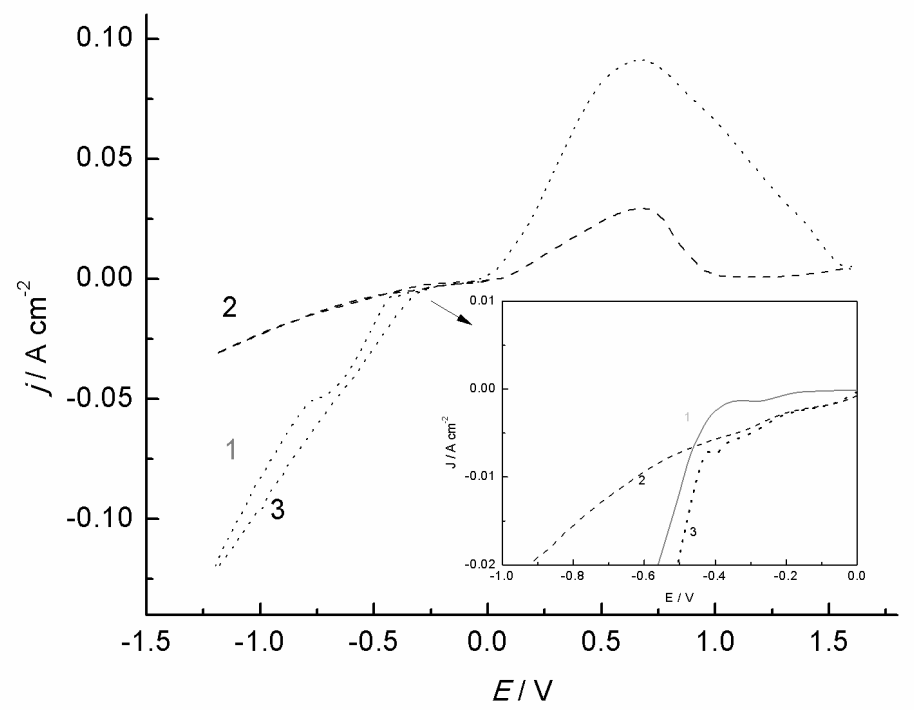

Figure 1.Cyclic voltammetry curves, obtained at $20 \mathrm{mV} \mathrm{s}^{-1}$ in the solution of: curve $1-75 \mathrm{~g} \mathrm{dm}^{-3}$ $\mathrm{K}(\mathrm{SbO}) \mathrm{C}_{4} \mathrm{H}_{4} \mathrm{O}_{6} \times 0.5 \mathrm{H}_{2} \mathrm{O}+96 \mathrm{~g} \mathrm{dm} \mathrm{D}^{-3} \mathrm{D}(-)-\mathrm{C}_{4} \mathrm{H}_{6} \mathrm{O}_{6}+20 \mathrm{mldm} \mathrm{dm}^{-3} \mathrm{CH}_{3} \mathrm{SO}_{3} \mathrm{H}$ (alloy electrolyte without $\mathrm{Cu}$ ); curve $2-8 \mathrm{gdm}^{-3} \mathrm{Cu} \mathrm{SO}_{4 \times} 5 \mathrm{H}_{2} \mathrm{O}+20 \mathrm{mldm} \mathrm{m}^{-3} \mathrm{CH}_{3} \mathrm{SO}_{3} \mathrm{H}+96 \mathrm{gdm}{ }^{-3} \mathrm{D}(-)-\mathrm{C}_{4} \mathrm{H}_{6} \mathrm{O}_{6}$ (alloy electrolyte without $\mathrm{Sb}$ ); curve 3- $8 \mathrm{~g} \mathrm{dm}^{-3} \mathrm{Cu} \mathrm{SO}_{4} \times 5 \mathrm{H}_{2} \mathrm{O}+75 \mathrm{gdm}^{-3} \mathrm{~K}(\mathrm{SbO}) \mathrm{C}_{4} \mathrm{H}_{4} \mathrm{O}_{6} \times 0,5 \mathrm{H}_{2} \mathrm{O}+20 \mathrm{mldm} \mathrm{Cm}_{3} \mathrm{SO}_{3} \mathrm{H}+$ $+96 \mathrm{~g} \mathrm{dm}^{-3} \mathrm{D}(-)-\mathrm{C}_{4} \mathrm{H}_{6} \mathrm{O}_{6}$ (alloy electrolyte)

Figure 2 and 3 present the dependence of the content of the coatings and the deposition rate on the current densities. With the increasing of the current density up to $0.8 \mathrm{~A} \mathrm{dm}^{-2}$ the content of $\mathrm{Sb}$ in the coatings increases from 0 to $80 \mathrm{wt}$. \% and reaches a plateau. At low current densities the coatings are pink, copper-like and at 0.3-0.4 $\mathrm{A} \mathrm{dm}$-2 some optical heterogeneity like darker spots and dots appear onto the cathodic surface. After $0.5 \mathrm{~A} \mathrm{dm}^{-2}$ the coatings are lilac and at the highest current densities (after $1.3 \mathrm{~A} \mathrm{dm}^{-2}$ ) they are shiny and stressed, with a lot of cracks. The deposition rate increases with increasing the current density up to $0.7 \mu \mathrm{m} \mathrm{min}^{-1}$, which is a relatively high deposition rate at similar electrolysis conditions compared to other alloy systems [8]. 


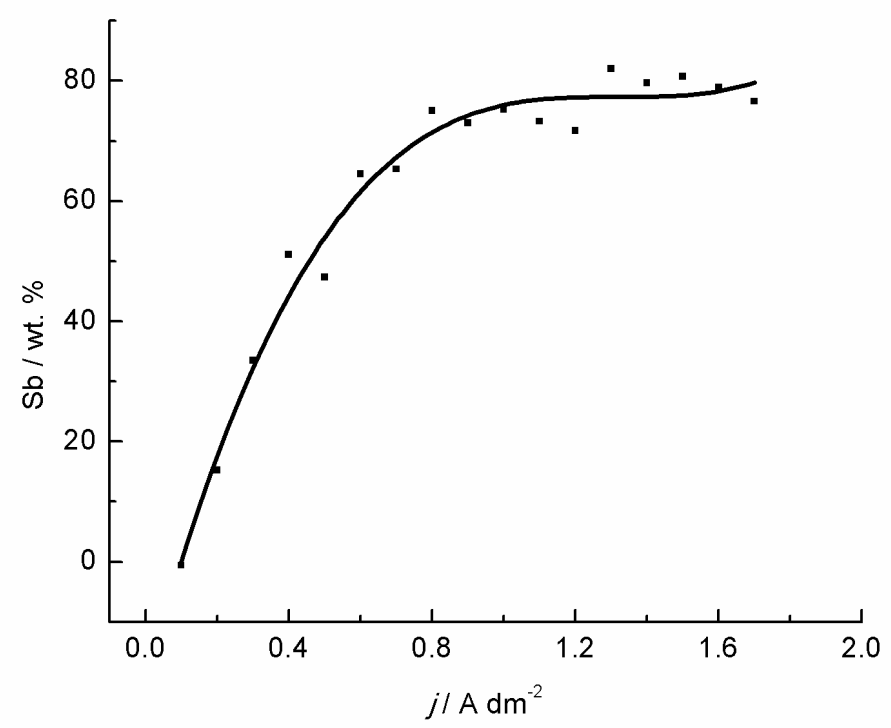

Figure 2. Effect of the current density on the antimony percentage in the coatings.

The composition of the electrolyte is presented in Table 1.

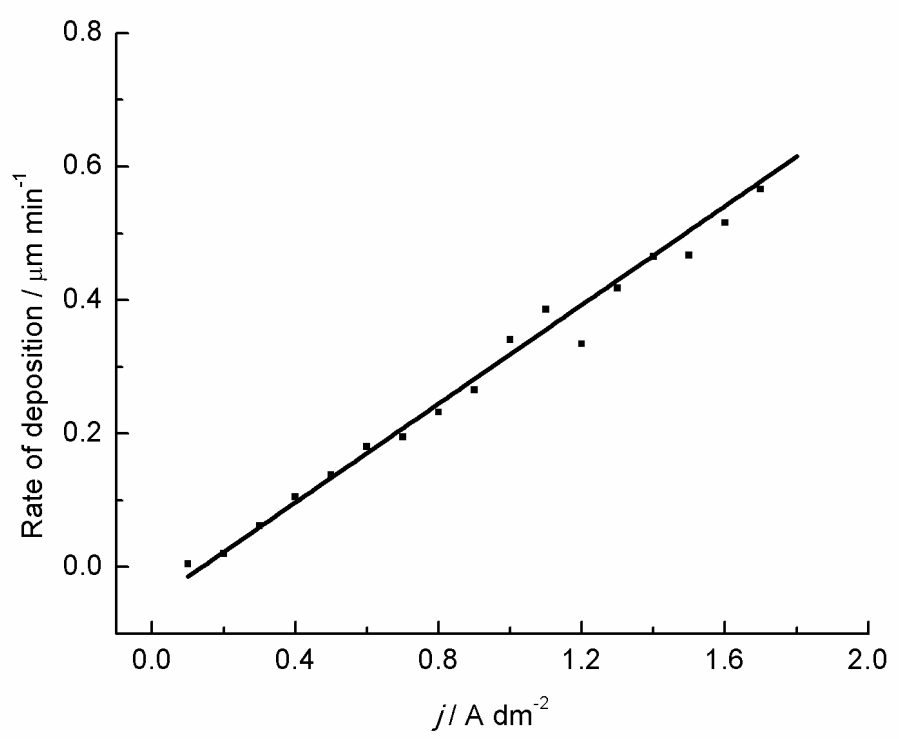

Figure 3. Effect of the current density on the deposition rate of the CU-Sb coatings. The composition of the electrolyte is presented in Table 1.

The morphology of the coatings, containing more than $60 \mathrm{wt} . \%$ of $\mathrm{Sb}$ is presented in the Figure 6 . The presence of aggregates (about $3 \mu \mathrm{m}$ each) with needle-like crystallites (not bigger than $1 \mu \mathrm{m}$ ) could be clearly seen. Moreover, there is a phase heterogeneity visible in the regime of back scattered electrons. Reasons for this conclusion gave the images on the left side of SPI electron microscopic image (Figure 4) - obtained in regime of back scattered electrons (BEI), while the right part of the photograph shows an image, obtained in regime of secondary electrons (SEI).

The heterogeneity is closely connected with the presence of more than one phase in the coatings. The proof of the phase heterogeneity is presented below.

Figure 5 shows the X-ray diffraction patterns of samples with different Sb-content. In the sample, containing $100 \mathrm{wt} \% \mathrm{Cu}\left(\right.$ at $0.1 \mathrm{~A} \mathrm{dm}^{-2}$ ) the reflexes of $\alpha$-Cu phase with a cubic lattice parameters $a=b=c=36.070 \mathrm{~nm}$ (ref. code 98-062-7117) together with the reflexes of the substrate of $\mathrm{Cu}_{2.6} \mathrm{Zn}_{1.4}$ (ref. code 98-062-9460) could be detected. 


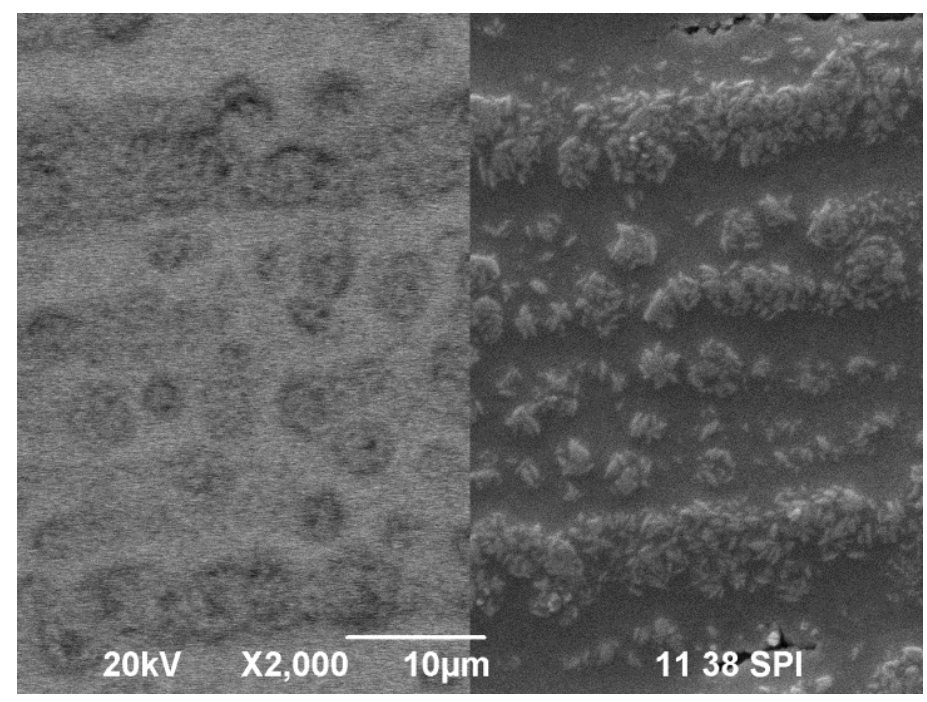

Figure 4. Scanning - electron image of the pink-lilac coatings with content 64.9 wt. \% Sb, 35.1 wt. \% Cu and thickness 3.6 $\mathrm{mm}$.

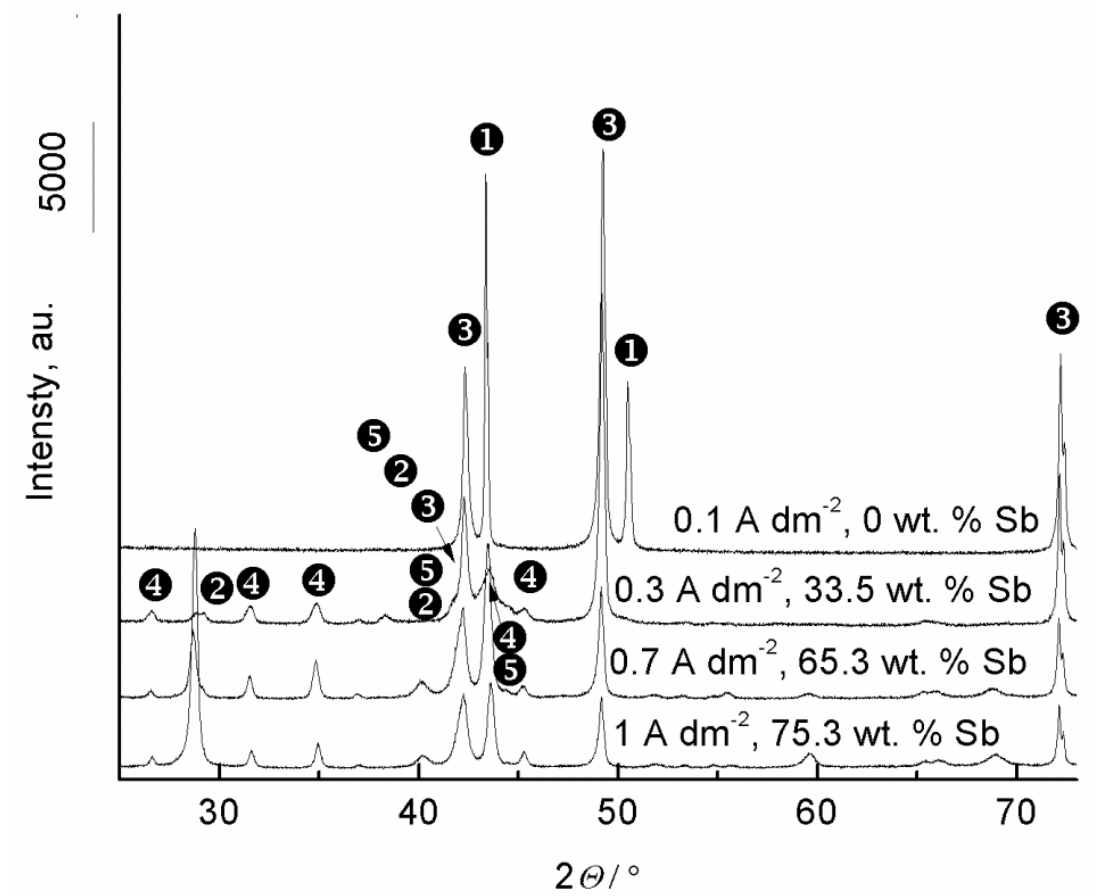

Figure 5. X-ray diffractograms of CU-Sb coatings with different antimony content, obtained in the electrolyte, presented in Table 1.The existed phases are marked with numbers 1 - $\mathrm{Cu} ; 2-\mathrm{Sb} ; 3-\mathrm{Cu}_{2.6} \mathrm{Zn} \mathrm{n}_{1.4} ; 4-\mathrm{Cu}_{2} \mathrm{Sb}_{1} ; 5-\mathrm{Cu}_{11} \mathrm{Sb}_{3}$

With increasing the current density to $0.3 \mathrm{~A} \mathrm{dm}^{-2}$ the content of $\mathrm{Sb}$ in the coating increases to $38 \mathrm{wt}$. \% and reflexes of the phase $\mathrm{Cu}_{2} \mathrm{Sb}$ whose lattice is tetragonal with parameters $\mathrm{a}=\mathrm{b}=4.002$ and $c=61.040 \mathrm{~nm}$ (ref. code 98-041-2295) could be observed. With increasing the content of antimony in the coatings up to 64-78 wt. \% the reflexes of the mentioned $\mathrm{Cu}_{2} \mathrm{Sb}$ phase and of a new-appearing $\mathrm{Cu}_{11} \mathrm{Sb}_{3}$ phase with orthorhombic lattice with parameters $a=4.3240, b=19.0800$, $c=4.7240$ (ref. code 98-010-3093) are detected. According to our knowledge the last mentioned phase is not presented in the literature as electrochemically obtained. In the paper of Hrussanova and Krastev only the presence of intermetallic $\mathrm{Cu}_{2} \mathrm{Sb}$ phase is reported [1]. Obviously additional characterization and comparison of this electrochemically obtained phase with a metallurgically obtained phase is needed. This phase, according to the phase diagram should be the $\xi$-phase, with the region of homogeneity from 42 to $58 \mathrm{wt}$. \%. At higher content of the Sb most probably the $\eta-$ phase of $\mathrm{Sb}$ is also presented (Figure 5). 
The next focus of this study was to find out the conditions of structure formation on the surface of the electrode. Based on theexperience with other alloy systems [13], and performing a large number of experiments the electrolysis conditions obtaining coatings with a wide variety of structures - left and right handed spirals, targets, even two-armed spirals (see Figure $6 b$ - in themiddle of the optical image) were established. The distance between two fronts of the structures $(\sim 100 \mu \mathrm{m})$ is about one order of magnitude higher thanin the case of the Ag-Sb structures [3]. The spatio-temporal structures are for the first time observed in the coppercontaining alloy system.

a

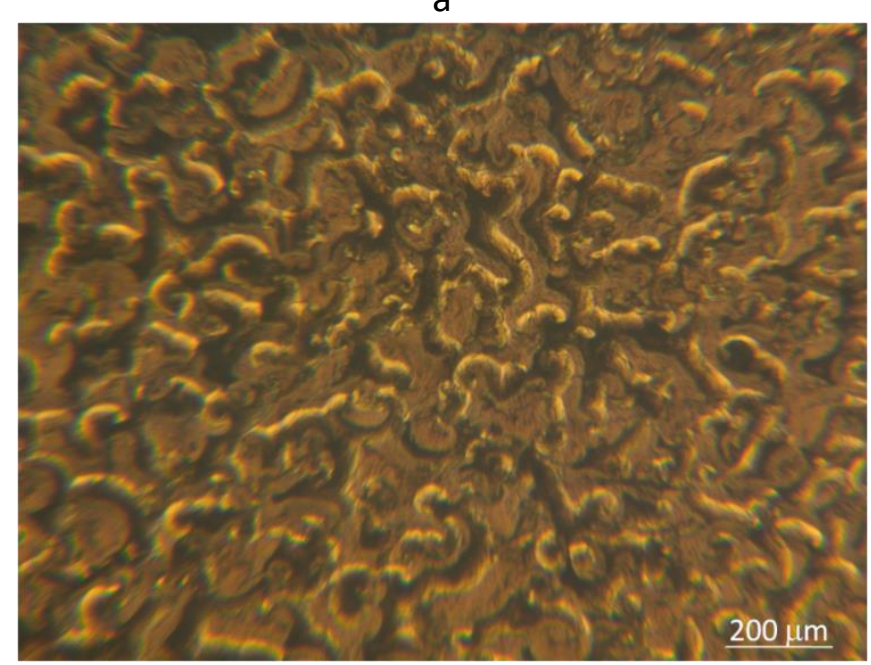

b

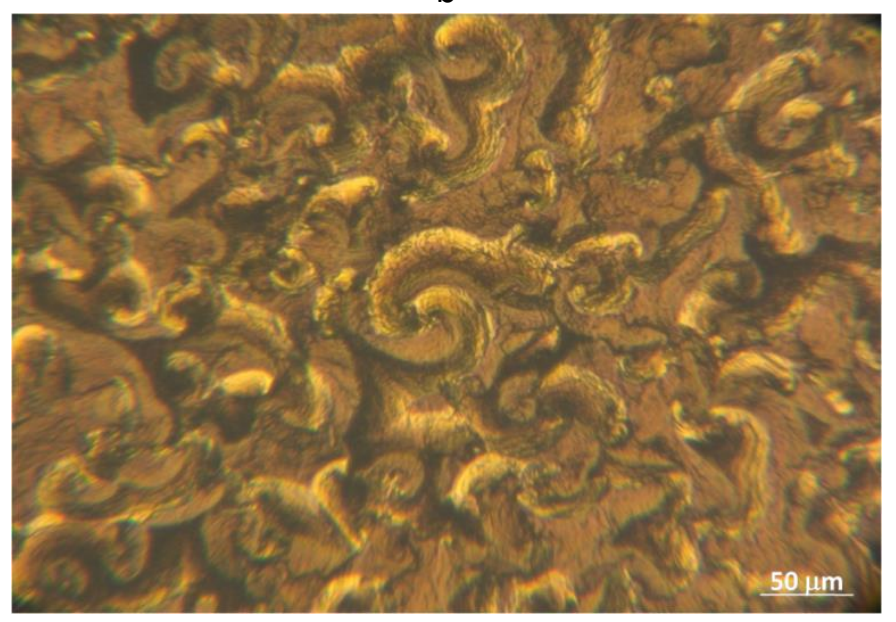

Figure 6. Optical images of the coating at different magnifications with spatio-temporal structures, obtained at: $\mathrm{j}=0.4 \mathrm{~A} \mathrm{dm}^{-2}$, deposition time- $240 \mathrm{~min}$, thickness $-23.76 \mu \mathrm{m}$

The results indicate that the spatio-temporal structuresare observed at a certain supersaturation and a specific adjustment of the ratio of the two metals in the electrolyte during the flow of a certain amount of electricity. The galvanostatic experiments on the reproducibility of the spiral pattern phenomena show that at certain $\mathrm{Cu}$ and $\mathrm{Sb}$ metal ratios in the electrolyte and at certain current densities the spiral structures can be observed in a fresh electrolyte without any preliminary electrolysis.

As shown in previous studies [8] the spatio-temporal structures appear onto the electrode surface due to some instabilities. Heterogeneous coatings are obtained as a result of random or ordered distribution of the different phases. So the phase composition of the patterned coating, 
shown in Figure 6 is presented in Figure 7. In this coating three phases $\mathrm{Sb}, \mathrm{Cu}_{2} \mathrm{Sb}, \mathrm{Cu}_{11} \mathrm{Sb}_{3}$ are registered. The burnt parts of the surface at the ends of the electrodes are rich of antimony and the structures are composed from two phases of the alloy $\mathrm{Cu}_{2} \mathrm{Sb}$ and $\mathrm{Cu}_{11} \mathrm{Sb}_{3}$.

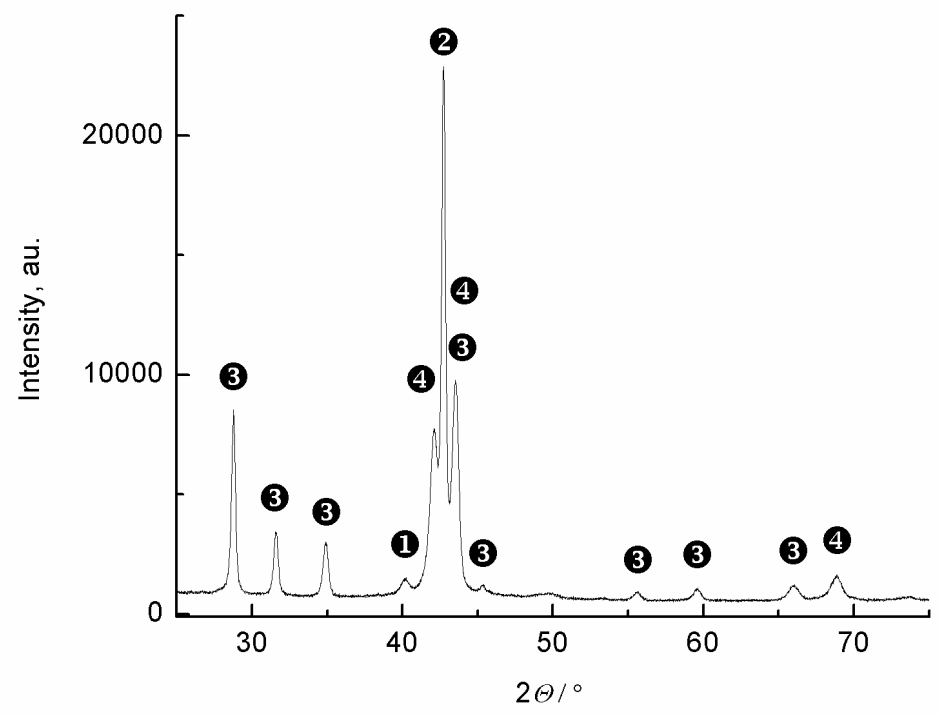

Figure 7. X-Ray diffractogram of the sample, shown in Figure 6. The registered phases are marked with numbers: $1-\mathrm{Sb} ; 2-\mathrm{Cu}_{2.6} \mathrm{Zn}_{1.4} ; 3-\mathrm{Cu}_{2} \mathrm{Sb}_{1} ; 4-\mathrm{Cu}_{11} \mathrm{Sb}_{3 .}$

\section{Conclusions}

The possibility to obtain copper-antimony alloy with up to 80 wt \% Sb from methanesulfonic acid is shown. The deposition rate, morphology and the phase composition of the obtained coatings are established. The phenomena of formation of spatio-temporal structures in this alloy are described. Most probably, the structures are formed by the phases $\mathrm{Cu}_{2} \mathrm{Sb}$ and $\mathrm{Cu}_{11} \mathrm{Sb}_{3}$.

Acknowledgments: The authors express their gratitude to Bulgarian National Science Fund for the financial support of project T02-27/2014.

\section{References}

[1] A. Hrussanova, I. Krastev, A. Zielonka, Zaštita Materijala 52 (2011) 145-151.

[2] I. Kristev, M. Nikolova and I. Nakada, Electrochim. Acta 34 (1989) 1219-1223.

[3] I. Kristev, M. Nikolova, J. Appl. Electrochem. 16 (1986) 867-874.

[4] I. Kristev, M. Nikolova, J. Appl. Electrochem. 16 (1986) 875-878.

[5] N. Dimitrova, T. Dobrovolska, I. Krastev, Arch. Metall. Mater. 58 (2013) 255-260.

[6] T. Dobrovolska, V. D. Jovic, B. M. Jovic, I. Krastev, J. Electroanal. Chem. 611 (2007) 232-240.

[7] I. Krastev,Ts. Dobrovolska, J. Eng.Proces. Management Intern. J 2 (2010) 99-105.

[8] I. Krastev, T. Dobrovolska, J Solid State Electrochem.17 (2013) 481-488.

[9] B. Bozzini, D. Lacitignola, I. Sgura, J. Solid State Electrochem. 17 (2013) 467-479.

[10] S. Fürtauer, H. Flandorfer, Monatsh Chem 143 (2012) 1275-1287.

[11] U. E. Klotz, Gold. Bull. 43 (2010) 4-10.

[12] J. Fischer-Bühner, A. Basso, M. Poliero, Gold. Bull. 43 (2010) 11-20.

[13] Ts. Dobrovolska, I. Krastev, Electrodeposition of silver-indium alloys, in Electrolysis: Theory, Types and Applications, Nova Science Publishers Inc, New York 2010,pp. 303-326.

(c) 2016 by the authors; licensee IAPC, Zagreb, Croatia. This article is an open-access article distributed under the terms and conditions of the Creative Commons Attribution license

(http://creativecommons.org/licenses/by/4.0/) 